\title{
Validating quantitative precipitation forecast for the Flood Meteorological Office, Patna region during 2011-2014
}

\author{
R K Giri ${ }^{1}$, Jagabandhu Panda ${ }^{2, *}$, Sudhansu S Rath ${ }^{2}$ and Ravindra Kumar ${ }^{1}$ \\ ${ }^{1}$ Regional Meteorological Centre Patna, Bihar, India. \\ ${ }^{2}$ Department of Earth and Atmospheric Sciences, National Institute of Technology Rourkela, Odisha, India. \\ ${ }^{*}$ Corresponding author.e-mail: pandaj@nitrkl.ac.in
}

In order to issue an accurate warning for flood, a better or appropriate quantitative forecasting of precipitation is required. In view of this, the present study intends to validate the quantitative precipitation forecast $(\mathrm{QPF})$ issued during southwest monsoon season for six river catchments (basin) under the flood meteorological office, Patna region. The forecast is analysed statistically by computing various skill scores of six different precipitation ranges during the years 2011-2014. The analysis of QPF validation indicates that the multi-model ensemble (MME) based forecasting is more reliable in the precipitation ranges of 1-10 and 11-25 mm. However, the reliability decreases for higher ranges of rainfall and also for the lowest range, i.e., below $1 \mathrm{~mm}$. In order to testify synoptic analogue method based MME forecasting for QPF during an extreme weather event, a case study of tropical cyclone Phailin is performed. It is realized that in case of extreme events like cyclonic storms, the MME forecasting is qualitatively useful for issue of warning for the occurrence of floods, though it may not be reliable for the QPF. However, QPF may be improved using satellite and radar products.

\section{Introduction}

Analysis relating to the distribution of satellitederived rainfall amounts is called quantitative precipitation estimation (QPE). And, the analysis relating to the forecasting of rainfall is called quantitative precipitation forecasting $(\mathrm{QPF})$. India Meteorological Department (IMD) and Indian Space Research Organization (ISRO) produce QPE and QPF from satellite and radar observations as well as the associated products through numerical modelling. These products are essential to analyse the amount of precipitation in extreme weather conditions as well as in a seasonal or climatological perspective. For example, Panda et al. (2015) utilized QPE from KALPANA-1 satellite in order to analyse the observed meteorological features during the occurrence of tropical cyclone PHET. A similar satellite product through GPS (Global Positioning System) network named integrated precipitable water vapour (IPWV) is used in the study of the surface and upper air meteorological characteristic features over Mumbai and Goa during the occurrence of Phyan tropical cyclone by Panda and Giri (2012). Thus, satellite-derived products including rainfall, IPWV as well as wind components are quite useful in the study of extreme weather events like cyclonic storms (Panda et al. 2011, 2015; Giri et al. 2012; Panda and Giri 2012) and the associated heavy rainfall events. In addition to the satellite and radar products, the quantitative analysis of rainfall can also be performed using automatic weather station (AWS) data sets (e.g., Agnihotri and Panda 2014). However, forecasting of rainfall during an extreme weather event can only be done through numerical modelling or using statistical approach.

Keywords. QPE; QPF; rainfall; flood; MME; Phailin. 
Increasing flood risk is now recognized as one of the important type of threats in the changing climate scenario especially in the perspective of extreme rainfall events. In several instances, the extreme weather leading to heavy rainfall events cause floods. Such events include cyclonic storms, thunderstorms and cloud bursts. In addition, heavy monsoonal precipitation may lead to flooding in the downstream areas of river basins (Mirza 2003) as well. Further, the glacier melting in the mountain regions may also cause flash floods (Das et al. 2015) as well. According to a study by Guhathakurta et al. (2011), extreme rainfall and associated flood risk is increasing in most parts of India except the central region. The primary reason for the occurrence of extreme events in India is quoted to be the climate change effects over this region. According to the extensive studies by Guhathakurta et al. (2011), the intensity of extreme rainfall has increased over coastal Andhra Pradesh and its adjoining areas, Saurashtra and Kutch, Odisha, West Bengal, parts of northeast India, and east Rajasthan. This study also indicates that the flood risk has increased significantly over India. The flood risk was more in the decades 1981-1990, 1971-1980 and 1991-2000. The increase of flood risk is also observed during the recent past mostly over the eastern coast, West Bengal, east Uttar Pradesh, Gujarat and Konkan regions. Irrespective of the reasoning, the floods occurring due to the extreme weather events in recent years caused property damage and human loss. In view of this, intensive and continuous research in this direction is inevitable since it helps in forecasting of such events.

Some of the flash floods originated due to heavy rainfall events over three metro cities Mumbai, Chennai and Bangalore in the year 2005 caused substantial damages in economy and loss of human life, etc. (Guhathakurta et al. 2011). According to IPCC report 2007, heavy rainfall events are projected to be severe in future besides increasing floods in the tropical areas (IPCC 2007). A large amount of the variability of precipitation is related to the occurrence of these heavy rainfall events and their intensities. Understanding of these extremes is therefore quite significant in the Indian perspective. Some authors analysed the associated rainfall relation in different synoptic situations prevailing over different regions in terms of occurrence, distribution and intensity. For example, Mohanty and Dimri (2004) studied for location-specific prediction of occurrence of the extreme rainfall events and quantity of precipitation over western Himalayas during winter period 1984-1996. Similarly, Ray and Patel (2000) and Ram and Kaur (2004) formulated QPF model by synoptic analogue method over Narmada and upper
Yammuna respectively in order to discuss about the flooding scenarios. Recently, Das et al. (2015) used several satellite-derived products in order to understand the glacier melting induced flood event in June 2013 over Kedarnath, Uttarakhand, India.

In tropical regions like India, weather forecasting by using statistical and numerical methods is quite useful for operational purpose. In view of this, quantitative precipitation forecast (QPF) might be done by adopting conventional synoptic analysis method since it can serve as a potential tool for operational flood forecasting purposes. A study by Dhar and Nandergi (1993) indicates how the synoptic weather situations are responsible for the occurrence of flood while analysing the spatial distribution of severe rainstorms over India and their associated areal rain depth. Lal et al. (1989) studied different types of synoptic situations and correlated them with the resulting rainstorms over Gomti river catchment area during 1976-1980 and prepared synoptic analogue for forecast range for areal rainfall. Several other studies like Ray and Sahu (1998) and Ram and Pangasa (2000) also adopted synoptic analogue method for the study of river basins and catchment areas. Similarly, Singh et al. (2010a, b) discussed about semi-quantitative forecasts for Baghmati or Adhwara Group of rivers, Kamala Balan and Kosi-Mahananda catchments by adopting synoptic analogue method. They emphasized that it is possible to issue semiquantitative precipitation forecast with greater accuracy.

Few other studies, on the other hand, suggest for consideration of multi-model ensemble (MME) based rainfall forecast (e.g., Krishnamurti et al. 1999; Das et al. 2011; Mitra et al. 2011; Roy Bhowmik and Durai 2012). According to these studies, MME-based QPF is relatively better, compared to the one from an individual model particularly during the monsoon season (Mitra et al. 2011; Roy Bhowmik and Durai 2012). Taking into account this, the current study intends to validate the MME-based QPF issued (by IMD) during southwest monsoon season for the region under Flood Meteorological Office, Patna (Bihar, India) for 2011-2014 period and examine whether the same is true for this area.

Details about the considered geographical area of interest are described in the following section. The data used in this study and adopted methodology are described in section 3. Section 4 contains the detailed analysis of data and associated scientific discussions. A special case of rainfall forecasting or $\mathrm{QPF}$ in the extreme weather conditions during the occurrence of tropical cyclone Phailin is discussed in section 5. Finally, the concluding remarks are presented in section 6 . 


\section{Geographical area of interest}

Bihar state is located in the eastern part of India between latitudes $24^{\circ} 20^{\prime} 10^{\prime \prime}-27^{\circ} 30^{\prime} 15^{\prime \prime} \mathrm{N}$ and longitudes $83^{\circ} 19^{\prime} 50^{\prime \prime}-88^{\circ} 17^{\prime} 40^{\prime \prime} \mathrm{E}$. The total geographical area of the region is about 93.60 lakh hectare, out of which 52.79 lakh hectares is agricultural land. The area is bounded by the Himalayas and Terai region of Nepal in the north, Mahananda (river) in the east, river Ganges in the south and river Gandak in the west. The considered area (figure 1) is rich in alluvial soils and is part of IndoGangetic plain. It comprises the tract of alluvial plains, north of Ganga, located between the Ganga and Indo-Nepal border and drained by the rivers like Burhi Gandak, Gandak, Mahananda and Kosi into Ganga. The river subsystems like BagmatiAdwara and Kamla-Balan, etc. also drain into Kosi through the river Ganga. The average rainfall over the state is about $1194 \mathrm{~mm}$ and varies from 1180 and $1210 \mathrm{~mm}$. Most of the rainfall (80$90 \%$ ) is received during mid-June to mid-October. The late September-October rains (locally known as 'Hathia'), though $50-100 \mathrm{~mm}$ in quantity, are crucial to agricultural activities in the region and their timing and distribution make the significant difference in order to determine whether it is plenty or scarce. The river Ganga, which flows in the middle of the region, divides the state into two halves as north and south Bihar. The considered region is primarily sub-tropical and humid in nature, which lies between humid West Bengal in

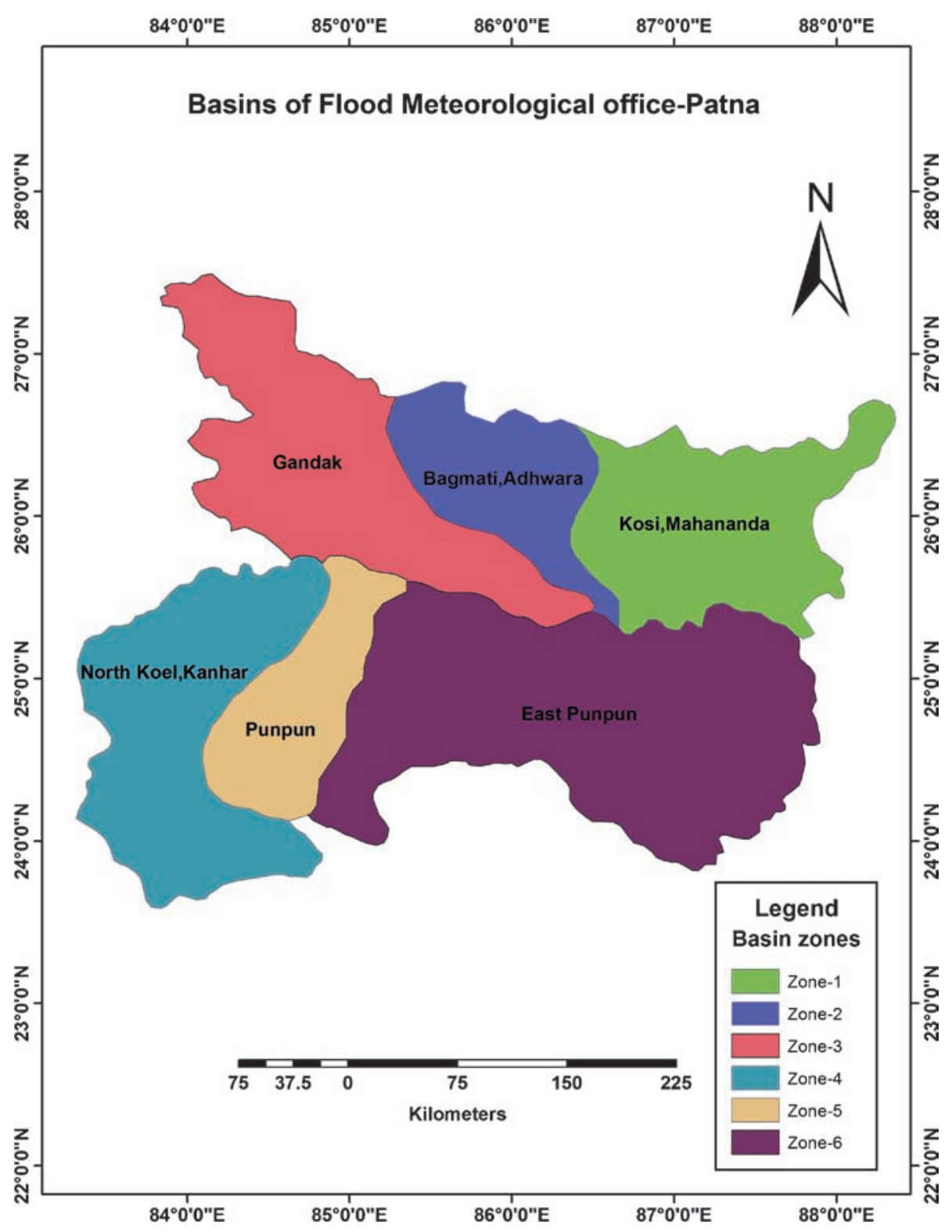

Figure 1. Basins of Flood Meteorological Office (FMO), Patna; a unit of India Meteorological Department. 
the east and subhumid Uttar Pradesh in the west. Bihar is the most vulnerable state for floods since they are an annually recurring affair affecting the human and livestock population, causing damage to agriculture, property and infrastructure.

\section{Data and methodology}

IMD has 10 FMO (Flood Meteorological Office) branches those are responsible for issuing the QPF (http://www.imd.gov.in/services/others/hydrometeorology-flood.htm) in the respective regions. The said regions are Agra, Asansol, Ahmedabad, Bhubaneswar, Guwahati, Hyderabad, Jalpaiguri, Lucknow, New Delhi and Patna. FMO Patna issues the forecast for six river catchments (figure 1; Zone 1: Kosi-Mahananda, Zone 2: Bagmati-Adhwara, Zone 3: Gandak, Zone 4: North Koel-Kanhar, Zone 5: Punpun and Zone 6: East-Punpun) twice a day for 48 hrs (recently modified to $72 \mathrm{hrs}$ ) and outlook for 3 days mainly during June-October. In case of severe weather, hourly inference or warnings are generated and disseminated to the concerned authority for further communication. In view of these aspects, observational data from several sources including satellite, Doppler Weather Radar (DWR) and in-situ observations based on isohyetal analysis are collected from 57 FMO stations (figure 2) during south-west monsoon season on a daily basis (table 1). Isohyetal analysis is usually a graphical technique that involves drawing of estimated lines of equal rainfall over an area based on station observations. In this technique, the magnitude and extent of the rainfall areas of coverage are subsequently considered with respect to the area of interest for estimating the areal precipitation value.

It may be noted that the basins of FMO Patna region map shown in figure 1 is created using Arc-GIS. For this purpose, the given basin outlines are considered for the preparation of maps. Similarly, GPS data set is used for preparing the map that shows the study locations, which are part of three neighbouring states Bihar, Jharkhand and Uttar Pradesh (figure 2). Out of 57 stations (table 1) in total, 49 stations are located within

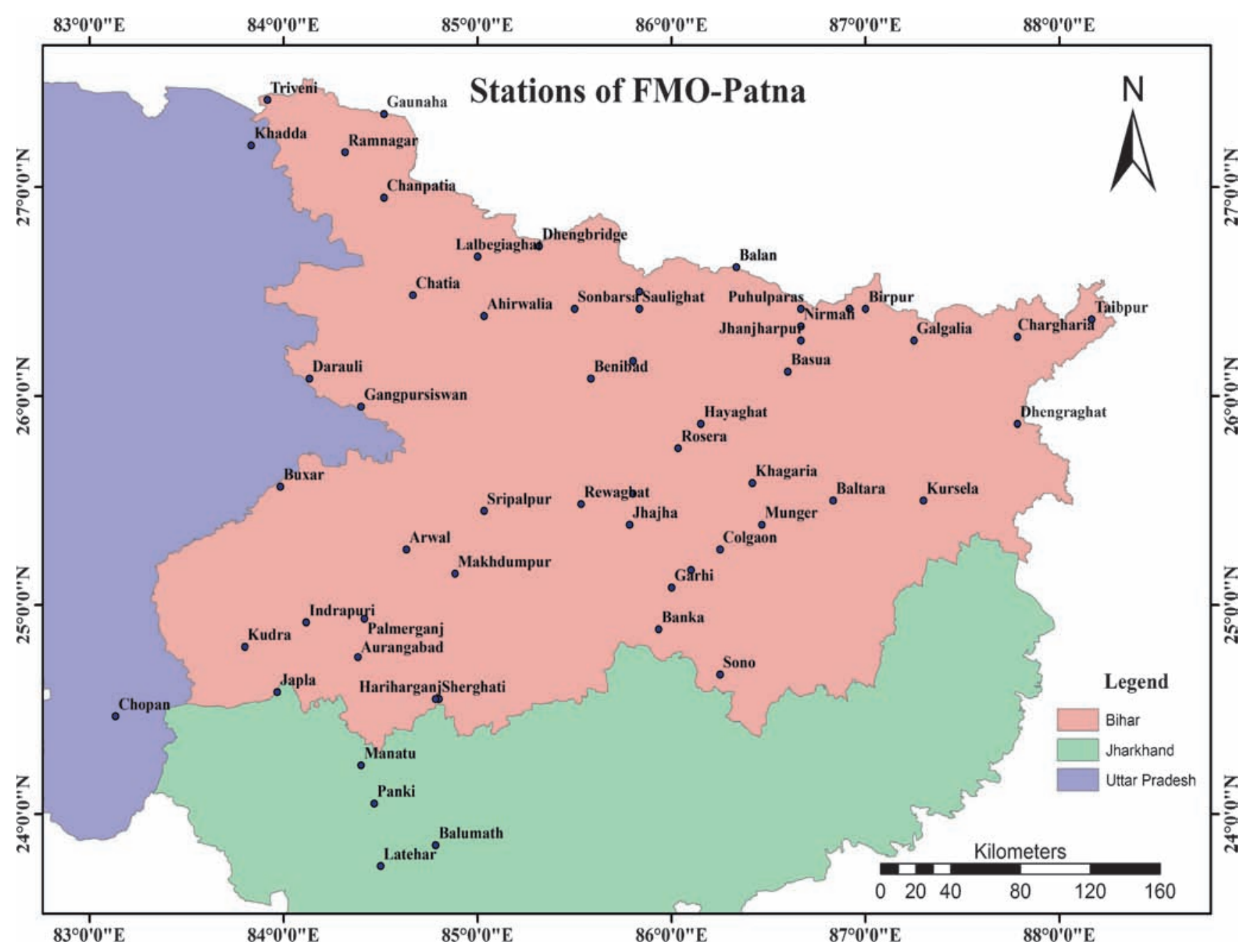

Figure 2. Stations considered in this study under FMO Patna region. 
Table 1. Geographical locations of the stations under FMO, Patna.

\begin{tabular}{|c|c|c|c|}
\hline Sl. no. & $\begin{array}{l}\text { Name of } \\
\text { station }\end{array}$ & $\begin{array}{l}\text { Altitude } \\
(\mathrm{m})\end{array}$ & Catchment \\
\hline 1 & Birpur & 55.0 & Kosi/Mahananda \\
\hline 2 & Bhimnagar & 56.0 & Kosi/Mahananda \\
\hline 3 & Basua & 49.1 & Kosi/Mahananda \\
\hline 4 & Nirmali & 50.0 & Kosi/Mahananda \\
\hline 5 & Dhengraghat & 30.0 & Kosi/Mahananda \\
\hline 6 & Baltara & 36.0 & Kosi/Mahananda \\
\hline 7 & Khagaria & 36.0 & Gandak/Buri-Gandak \\
\hline 8 & Kursela & 23.0 & Kosi/Mahananda \\
\hline 9 & Taibpur & 66.9 & Kosi/Mahananda \\
\hline 10 & Chargharia & 44.4 & Kosi/Mahananda \\
\hline 11 & Galgalia & 78.2 & Kosi/Mahananda \\
\hline 12 & Sonbarsa & 78.0 & K-Balan/Bug/Adhw \\
\hline 13 & Dhengbridge & 65.0 & K-Balan/Bug/Adhw \\
\hline 14 & Madhawapur & 56.0 & K-Balan/Bug/Adhw \\
\hline 15 & Balan & 71.9 & K-Balan/Bug/Adhw \\
\hline 16 & Puhulparas & 55.0 & K-Balan/Bug/Adhw \\
\hline 17 & Saulighat & 45.0 & K-Balan/Bug/Adhw \\
\hline 18 & Jhanjharpur & 44.3 & K-Balan/Bug/Adhw \\
\hline 19 & Kamtaul & 44.0 & K-Balan/Bug/Adhw \\
\hline 20 & Hayaghat & 35.0 & K-Balan/Bug/Adhw \\
\hline 21 & Triveni & 105.0 & Gandak/Buri-Gandak \\
\hline 22 & Chanpatia & 75.0 & Gandak/Buri-Gandak \\
\hline 23 & Ramnagar & 95.0 & Gandak/Buri-Gandak \\
\hline 24 & Gaunaha & 93.5 & Gandak/Buri-Gandak \\
\hline 25 & Lalbegiaghat & 65.0 & Gandak/Buri-Gandak \\
\hline 26 & Ahirwalia & 58.0 & Gandak/Buri-Gandak \\
\hline 27 & Chatia & 62.0 & Gandak/Buri-Gandak \\
\hline 28 & Samastipur & 48.0 & Gandak/Buri-Gandak \\
\hline 29 & Rosera & 43.0 & Gandak/Buri-Gandak \\
\hline 30 & Darauli & 68.0 & Gandak/Buri-Gandak \\
\hline 31 & Gangpursiswan & 68.0 & Gandak/Buri-Gandak \\
\hline 32 & Benibad & 40.0 & K-Balan/Bag/Adhwa \\
\hline 33 & Rewaghat & 51.2 & Gandak/Buri-Gandak \\
\hline 34 & Indrapuri & 460.0 & Koel/Kanahar/Sone \\
\hline 35 & Arwal & 71.3 & Punpun \\
\hline 36 & Buxar & 50.7 & Koel/Kanahar/Sone \\
\hline 37 & Aurangabad & 139.0 & Punpun \\
\hline 38 & Palmerganj & 139.0 & Punpun \\
\hline 39 & Sherghati & 113.0 & Punpun \\
\hline 40 & Makhdumpur & 104.0 & Punpun \\
\hline 41 & Sripalpur & 53.4 & Punpun \\
\hline 42 & Munger & 32.0 & Ganga/E-Punpun \\
\hline 43 & Banka & 354.0 & Ganga/E-Punpun \\
\hline 44 & Colgaon & 25.2 & Ganga/E-Punpun \\
\hline 45 & Lakhisarai & 44.8 & Ganga/E-Punpun \\
\hline 46 & Sono & 119.2 & Ganga/E-Punpun \\
\hline 47 & Garhi & 539.4 & Ganga/E-Punpun \\
\hline 48 & Jhajha & 510.0 & Ganga/E-Punpun \\
\hline 49 & Kudra & 324.0 & Koel/Kanahar/Sone \\
\hline 50 & Panki & 419.0 & Koel/Kanahar/Sone \\
\hline 51 & Japla & 225.0 & Koel/Kanahar/Sone \\
\hline 52 & Manatu & 584.0 & Koel/Kanahar/Sone \\
\hline 53 & Hariharganj & 453.0 & Ganga/E-Punpun \\
\hline 54 & Balumath & 360.0 & Koel/Kanahar/Sone \\
\hline 55 & Latehar & 44.3 & Koel/Kanahar/Sone \\
\hline 56 & Khadda & 92.0 & Gandak/Buri-Gandak \\
\hline 57 & Chopan & 155.4 & Koel/Kanahar/Sone \\
\hline
\end{tabular}

Bihar region whereas six are in Jharkhand and remaining two stations are in Uttar Pradesh (figure 2). The generic state boundaries are referred while reproducing the location map (using Arc-GIS) of all of these 57 stations in the FMO Patna region. Spatial co-ordinate references are considered in figure 1 since the catchment areas are specific in view of the particular nature of FMO as per the policies of IMD.

The objective of this study is primarily to validate MME-based QPF by using the station and KALPANA-1 satellite observations for FMO Patna region during 2011-2014 monsoon seasons. And the considered special case of extreme precipitation during the occurrence of Phailin plays a supportive role for the present study as far as the MMEbased flood forecasting is concerned. The station or in-situ observations are from IMD. KALPANA1 QPE values are produced using INSAT MultiSpectral Rainfall Algorithm (IMSRA) at a similar horizontal resolution as that of MME for comparison purpose.

MME is prepared by using gridded global/ regional analysis/reanalysis data sets from numerical models such as NCEP (National Center for Environmental Prediction) GFS (Global Forecasting System) T-382 from United States, JMA (Japanese Meteorological Agency) T-859, ECMWF (European Centre for Medium Range Weather Forecasts) T-799, NCMRWF (National Centre for Medium Range Weather Forecasting) T-254 from India and United Kingdom Meteorological Office (UKMO) global model through synoptic analysis method. An appropriate weight for each gridded analysis/reanalysis from these models is considered for the preparation of MME-based QPF. For NCEP GFS model, the weight ranges from 0.31 to 0.21 . For ECMWF model, these values range from 0.35 to 0.27 ; for JMA model, the range of corresponding weights is $0.40-0.28$; for NCMRWF regional analysis, the range, is $0.35-$ 0.25 and for UKMO model, the values range from 0.40 to 0.32 (Roy Bhowmik and Durai 2012). Using the method adopted by Mitra et al. (2011) and Roy Bhowmik and Durai (2012), the MME-based QPF is prepared at IMD for the years 2011-2012. However, due to the unavailability of gridded analysis from several models, a locally run GFS model named as IMD GFS T-574 is used along with NCEP GFS T-382 and JMA T-859 for the preparation of MME-based QPF for the years 2013 and 2014 by adopting a linear averaging technique or by using equal weights. Each of these gridded analysis datasets is of $0.25^{\circ} \times$ $0.25^{\circ}$ horizontal resolution and the models used for the production of them adopt similar physical parameterizations. 
Based on the collected observations and model forecasts, QPF is usually issued twice daily for $48 \mathrm{hrs}$ with weather outlook of $72 \mathrm{hrs}$ (including warning) in six different ranges (viz., 0.0, 01-10, 11-25, 26-50, 51-100 and >100 mm). However, it is essential to verify whether the MME-based QPF produced by IMD is at par with the observation. In view of this, the $\mathrm{QPF}$ validation is discussed briefly in the following section.

\section{Discussing QPF validation}

QPF refers to the quantity of rainfall expected at a location or in a catchment during a specific period of time such as 12 or 24 hrs ahead. QPF by synoptic analogue method (e.g., Gibergans-Báguena and Llasat 2007; Mohanty et al. 2001) is relatively simple and quick for the forecasting of flood over a catchment area for different intervals. Such type of QPF is very useful for various planning and management purposes like flood related management in an area and associated agricultural planning, etc. In view of this, QPF over Patna region bears its significance as far as occurrence of floods is concerned and thus, needs to be done in an appropriate manner. There are different phases in the subsequent development of $\mathrm{QPF}$ over this region. Initially during the year 2011, simple arithmetic mean method was adopted. This method is used to compute the average areal precipitation (AAP) using all of the available station or point observations over the region of interest. However, this may not be appropriate and meaningful always. AAP values by the method of isohyetal contour analysis are more correct and meaningful, especially, when data received is sparse over any catchment area. In such a scenario, simple arithmetic mean method may give absurd result as compared to what is obtained by isohyetal contour analysis. At later stage, the $\mathrm{QPF}$ values are modified based on MME (Apte et al. 2011) forecasting, satellite and DWR estimated total precipitation area accumulation (PAC) values.

The objective of forecast verification is usually to determine its quality. In order to carry out this verification, it is necessary to relate the values obtained by a specific forecasting method with the corresponding observations. Thus, validating QPF with respect to the observations requires statistics based analysis using various statistical parameters (e.g., Mitra et al. 2011). The verification measures used in this study are POD (probability of detection), FAR (false alarm rate), MR (missing rate), BIAS of occurrence, C-NON (or correctnon-occurrence), CSI (critical success index), TSS (true skill score), HSS (heidke skill score), and $\mathrm{PC}$ (percentage correct). Such types of verification
Table 2. Skill score range.

\begin{tabular}{lc}
\hline Skill score & $\begin{array}{c}\text { Range for best / } \\
\text { perfect forecast }\end{array}$ \\
\hline Probability of detection (POD) & 1 \\
False alarm rate (FAR) & 0 \\
Missing rate (MR) & 0 \\
Correct-non occurrence (C-Non) & 1 \\
Critical success index (CSI) & 1 \\
Bias for occurrence (BIAS) & 1 \\
Percentage correct (PC) & $100 \%$ \\
True skill score (TSS) & 1 \\
Heidke skill score (HSS) & 1 \\
\hline
\end{tabular}

measures are also used by several researchers for precipitation forecast validation as well as other meteorological variables (e.g., Mohanty et al. 2001; Mandal et al. 2007). The ranges of these statistical parameters signifying the forecasting skill are given in table 2 . The details about these indices are given in Appendix. These statistical skill scores for the FMO Patna region for 2011-2014 are graphically presented in figures $3-11$ as well.

\subsection{Probability of occurrence of flood}

According to Mohanty et al. (2001), observed rainfall amounts can be classified in to four groups: (i) very light $(0.1-1.0 \mathrm{~mm})$, (ii) light $(1.1-10.0 \mathrm{~mm})$, (iii) moderate $(10.1-30.0 \mathrm{~mm})$, and (iv) heavy $(\geq 30.1 \mathrm{~mm})$. This study took into account observational data during 1985-1990. On the other hand, there is a chance of having extreme cases with more than $100 \mathrm{~mm}$ rainfall (e.g., Goswami et al. 2006; Guhathakurta et al. 2011) causing floods depending upon the geographical location and therefore, daily rainfall may be a case of extremism but not the yearly average one. Thus, various precipitation ranges of rainfall like $0-1$ or $<1,1-10,11-25,26-$ $50,51-100$ and $>100 \mathrm{~mm}$ can be considered for the yearly average values of rainfall in a reasonable manner in order to discuss the verification measures in view of the QPF validation and flood detection depending upon the availability of data. Figure 3 indicates that the probability of occurrence of flood events is $<50 \%(\mathrm{POD}<0.5)$ when the yearly average rainfall is below $1 \mathrm{~mm}$ during 2011-2014. However, the probability of occurrence of flood increases up to $86 \%$ (in the year 2011) when the yearly average rainfall is usually a moderate value between 1 and $10 \mathrm{~mm}$. And, the probability of detection gradually decreases from 2011 to 2014 in this range. In the precipitation range of $11-25 \mathrm{~mm}$, the maximum probability of detection of floods is $54 \%$ in the year 2014, otherwise the probability remains between 40 and $43 \%$. In the precipitation range $26-50 \mathrm{~mm}$, the probability of occurrence of flood decreases up to a maximum value of $20 \%$ (in the year 2013) whereas in 


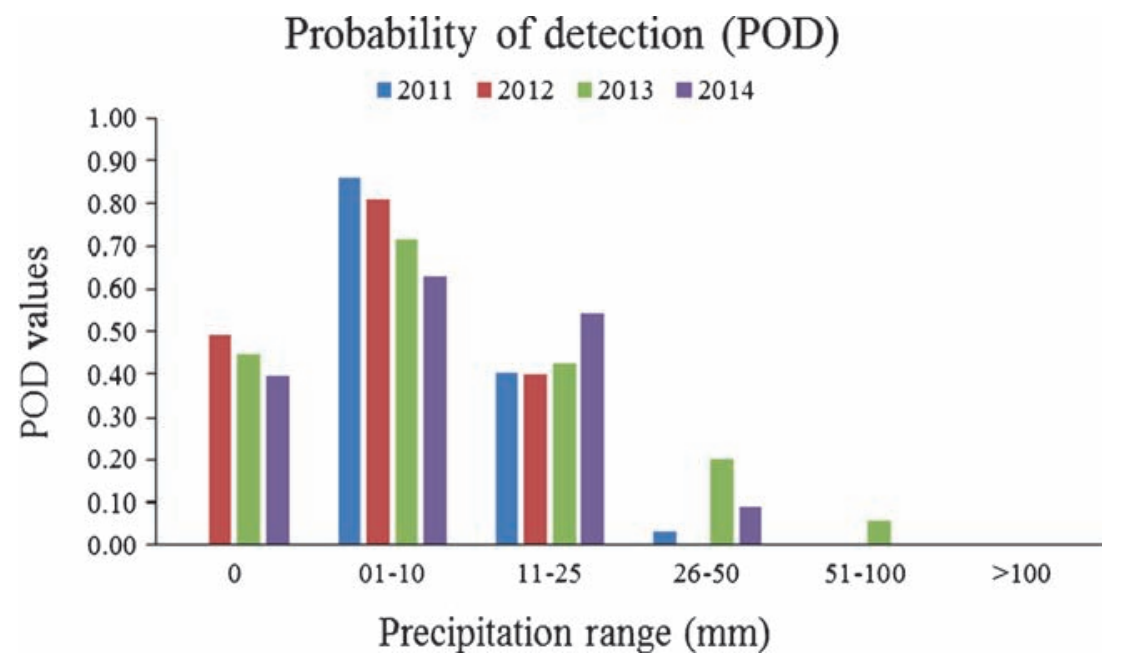

Figure 3. Probability of detection (POD) for the FMO Patna region during 2011-2014.

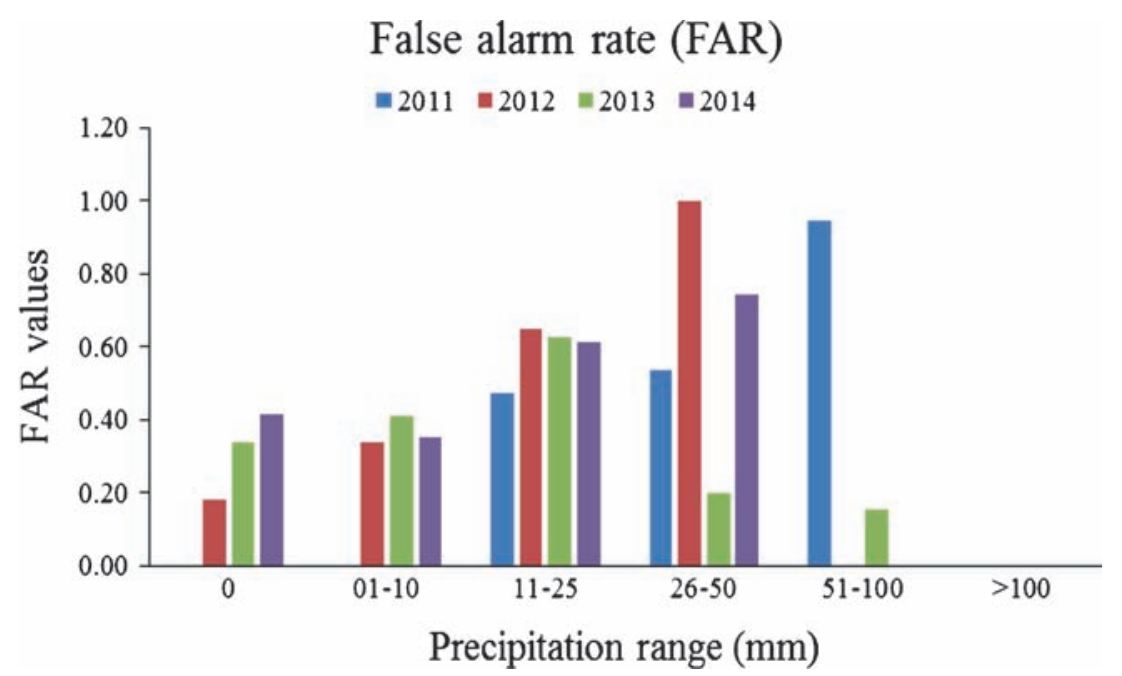

Figure 4. False alarm rate (FAR) for the FMO Patna region during 2011-2014.

the range $51-100 \mathrm{~mm}$, the maximum probability is 6\% (in the year 2013 again). It indicates that the probability of occurrence of floods is maximum when the yearly average rainfall lies in the range 1-10 mm, which comes under light rainfall category (Mohanty et al. 2001). However, it may be noted that the probability of occurrence of floods in FMO Patna region is $>50 \%$ when the yearly average rainfall is from light to moderate. This may be because, the duration of occurrence of rainfall is quite important for determining the probability of occurrence of floods as compared to the occurrence of an extreme event for a shorter duration when the time scale consideration is of yearly basis.

In general, when POD values are higher (figure 3), FAR values are reasonably found to be lower (figure 4). Further, it is noticed that FAR values are relatively low for lower $(\leq 10 \mathrm{~mm})$ and higher ranges $(>50)$ of yearly averaged precipitation though some exceptions are seen in case of 2011. The values of FAR can be reduced significantly by using the latest developed rainfall products judiciously.

Variation of MR for each year is found to be almost opposite to that of POD, i.e., for maximum (minimum) POD values $\mathrm{MR}$ is minimum (maximum) as evident from the comparison of figures 3 and 5 . The reason is quite obvious since the higher (lower) probability of occurrence should in principle correspond to lower (higher) values of MR. 'MR' values are found to be $\sim 1.0$ for the higher precipitation ranges (i.e., $26-50,51-100$ and $>100 \mathrm{~mm}$ ) for the year 2011. Such a characteristic feature is also noticed for rainfall range below $1 \mathrm{~mm}$. On the other hand, the variation of MR in the lower ranges, i.e., $1-10$ and $11-25 \mathrm{~mm}$ are found to be significantly different with relatively lower values for 1-10 $\mathrm{mm}$ range as compared to 11-25 mm range for each year (figure 5). 


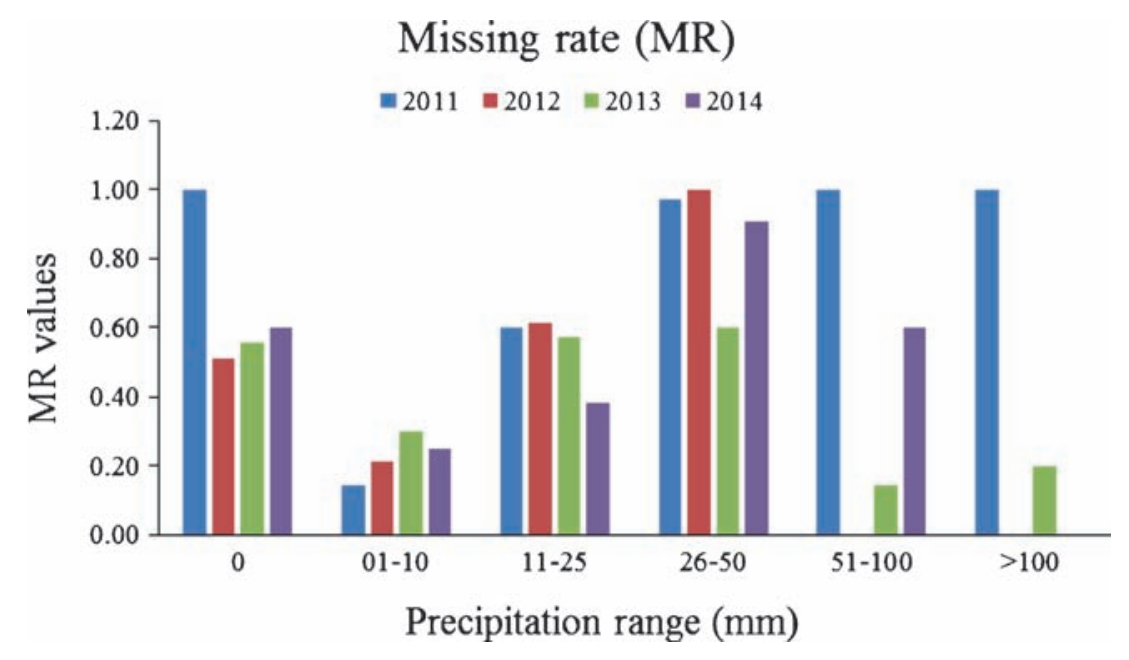

Figure 5. Missing rate (MR) for the FMO Patna region during 2011-2014.

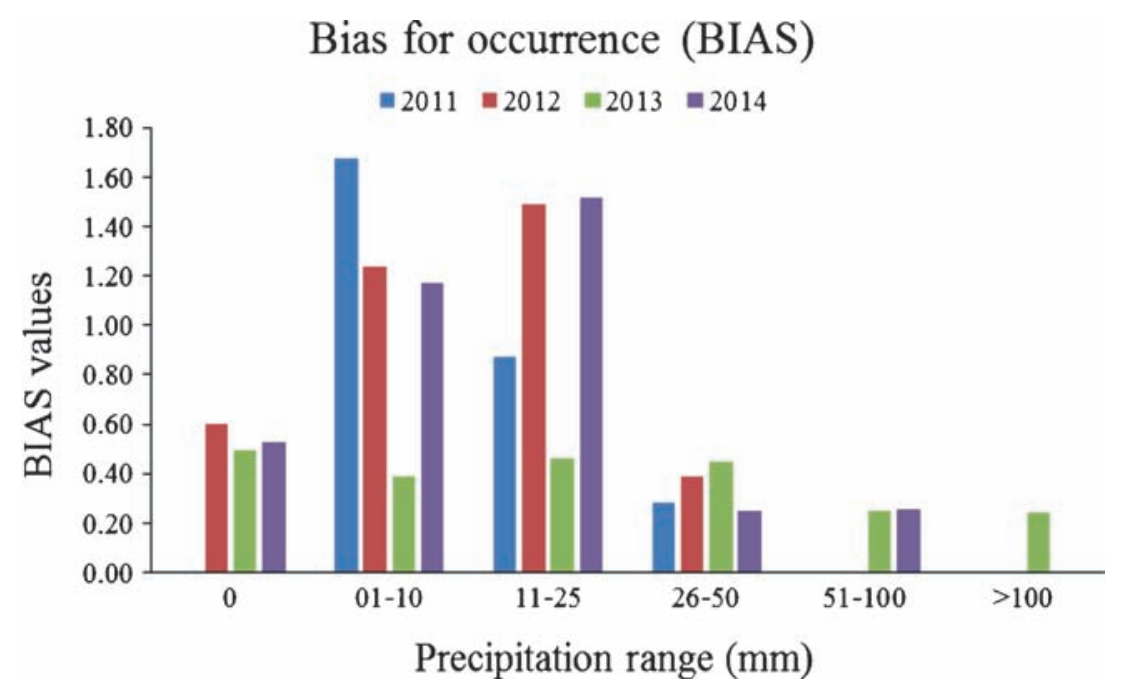

Figure 6. BIAS of occurrence of flood over the FMO Patna region during 2011-2014.

The variation of mean error or BIAS (figure 6) indicates that the QPF is whether underpredicted or overpredicted. The current analysis indicates that BIAS is relatively higher (0.87-1.68) in the precipitation ranges $1-10 \mathrm{~mm}$ and $11-25$ for the years 2011, 2012 and 2014 as compared to the other ranges. Moreover, the bias values are very high in the year 2014 as compared to the year 2013 for these precipitation ranges. And, the year 2013 shows a redundant variation (0.25$0.5)$. It may be noted that during the monsoon season once a synoptic system is well established, this can be well captured by a model. However, in the initiation stage, capturing the accurate rainfall in each catchment is relatively difficult. During the year 2014, spatial inhomogeneity in the initial stage of capturing the model predicted and actual rainfall was more as compared to the year 2013. This could be the possible reason for the higher bias values in 2014 as compared to 2013 (figure 6).

Figure 7 indicates that the predicting capability of the non-occurrence of flood events is $\geq 97 \%$ in the higher precipitation ranges, i.e., $26-50,51-100$ and $>100 \mathrm{~mm}$ for all the years. On the other hand, the probability of non-occurrence of floods is quite low in the range $1-10 \mathrm{~mm}$ and relatively higher in the range $11-25 \mathrm{~mm}$ as compared to the earlier. Thus, the probability of occurrence of floods should be maximum in the range $1-10 \mathrm{~mm}$ and thereby, corresponds to the higher POD values in this range (figure 3).

\subsection{Demonstrating skill scores and forecasting accuracy}

The skill scores for the QPF can be represented by CSI, TSS and HSS. CSI is an indicator of warning 


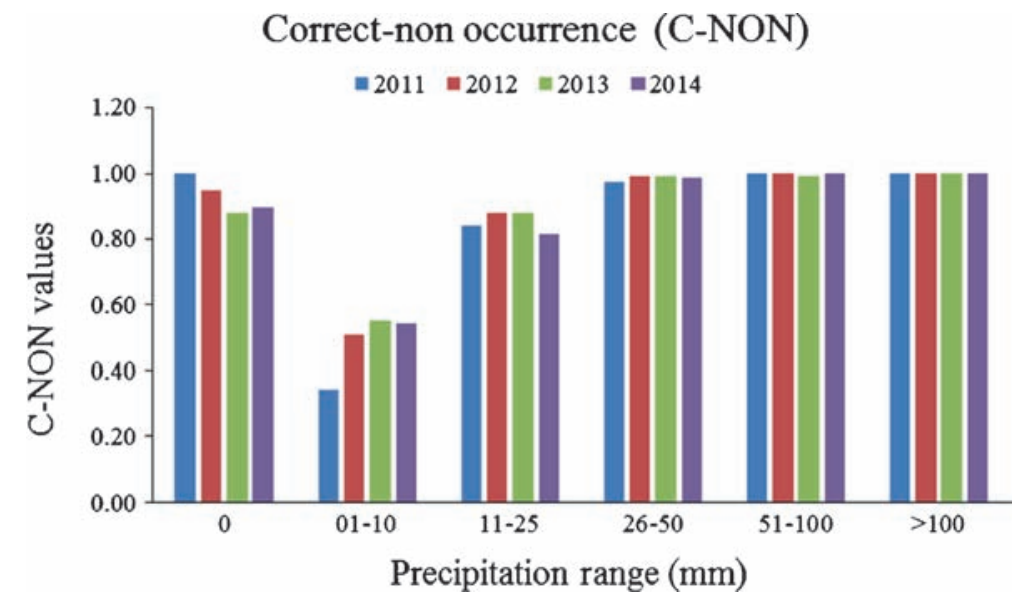

Figure 7. Correct non-occurrence (C-NON) of flood over the FMO Patna region during the years 2011-2014.

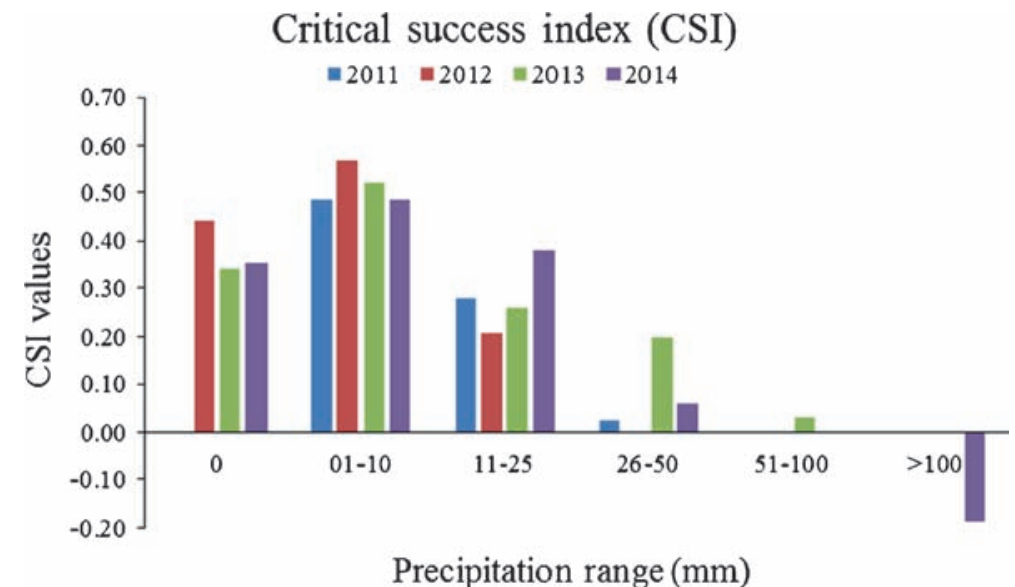

Figure 8. Critical success index (CSI) for forecasting of flood over the FMO Patna region during the years $2011-2014$.

skill (Schaefer 1990). This verification statistics skill score assumes that the times when an event is neither expected nor observed are of no consequence. It is not an unbiased indicator of forecast skill (since it is proportional to the frequency of the event being forecast) though it is used by several researchers for forecast verification purposes (e.g., Mohanty et al. 2001; Gerapetritis and Pelissier 2004; Mandal et al. 2007). CSI is a non-linear function of both FAR and POD and can explicitly be defined as a function of them (Schaefer 1990):

$$
\mathrm{CSI}=\frac{1}{\frac{1}{1-\mathrm{FAR}}+\left(\frac{1}{\mathrm{POD}}\right)-1}
$$

It is always better to issue warning when an event actually occurs otherwise not (Gerapetritis and Pelissier 2004). In order to achieve this perfection, one needs to have a POD of 1 , FAR of 0 and CSI value as 1 (table 2). On the other hand, this is always not possible since the forecaster will never know about the certainty of the occurrence of the event. This is even next to impossible in a situation when the analysis is done by considering the yearly variation of any meteorological parameter. If the success has to be measured through CSI, it is always better to consider the fact of strategic selection of a warning threshold such that CSI has the greatest likelihood of being maximized. In the present study, the ranges of precipitation are therefore carefully chosen by taking into account available literatures in Indian region and long term operational forecasting experience of IMD. The variation of CSI for considered ranges of precipitation (figure 8) indicates that the CSI values being larger in the lower $(<0,1-10 \mathrm{~mm})$ to light or moderate $(11-25 \mathrm{~mm})$ precipitation ranges, indicate maximization of its role for determining the QPF skill.

Like CSI, TSS and HSS also help in determining the forecasting skills and act as verification measures (refer Appendix for details). TSS measures discrimination power of the forecasting tool or model in general for different precipitation ranges (Mandal et al. 2007). In general, it can be seen that the forecasting skill is relatively better in detecting the occurrence of floods in the lower ranges of rainfall (figure 9). Similar is the case for HSS as 
well (figure 10). The overall percentage of correct forecast ranges between 57.5 and $100 \%$ (figure 11) indicating a good operational forecasting skill for QPF during 2011-2014. However, it is evident from TSS values that the MME-based QPF is relatively better compared to the other years for the precipitation range 11-25 $\mathrm{mm}$ (figure 9) whereas HSS values show the same is true for all precipitation ranges. This is because the monsoon rainfall events prevailed for more number of days during the year 2014 as compared to other years and in all of the models used for preparation of MME, they were matured enough to be well captured and better predicted.

Figure 12 shows the overall categorical accuracy for all the six zones (combined) of the region. One step down means whatever range we have forecasted; the precipitation will be acceptable one step ahead. Suppose we have forecasted 11-25 precipitation range and the rainfall occurs in $26-50 \mathrm{~mm}$ (one step ahead), then this range will also be counted correct forecast. In this way, figure 12 shows that by changing the method arithmetic mean to AAP (areal average precipitation) and then value addition by numerical weather prediction, satellite or radar, the accuracy in forecasting can be enhanced. In almost all cases (years), the performance in the precipitation range $11-25 \mathrm{~mm}$ is similar and most of the precipitations lie in this range. The values of POD (figure 3), CSI (figure 8), TSS (figure 9), HSS (figure 10) and PC (figure 11) are higher compared to other categories or ranges. Similarly, the FAR values (figure 4) are in general higher in 11-25 mm category compared to others with some exceptions.

\section{Special case during tropical cyclone Phailin}

The very severe (or category 5) tropical cyclone Phailin was originated from a remnant cyclonic circulation from the South China Sea (IMD 2013). It was located as a marked low pressure system in Bay of Bengal (BOB) on October 6, 2013 off

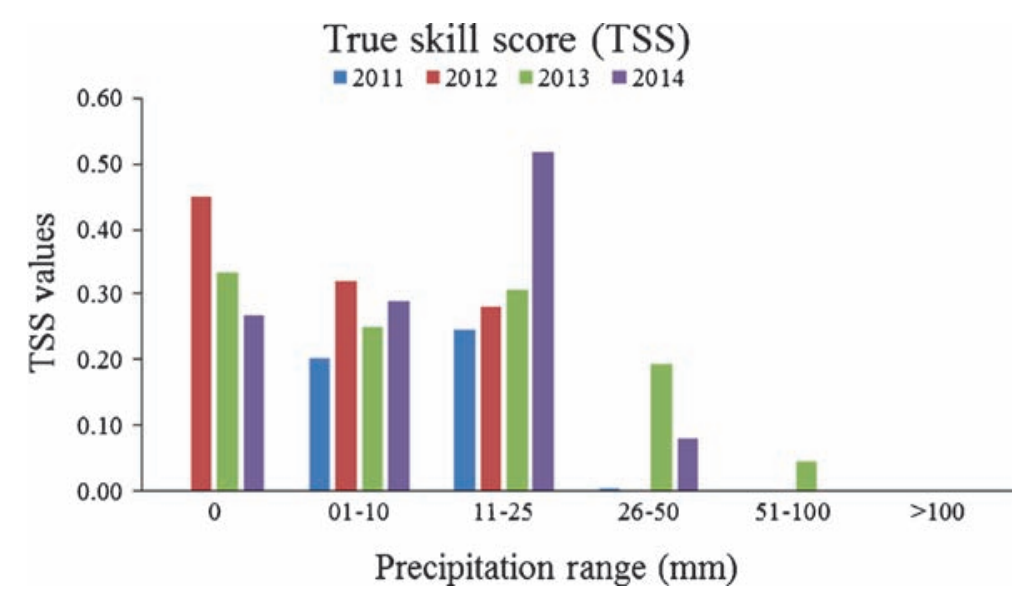

Figure 9. True skill score (TSS) for forecasting of flood over the FMO Patna region during the years 2011-2014.

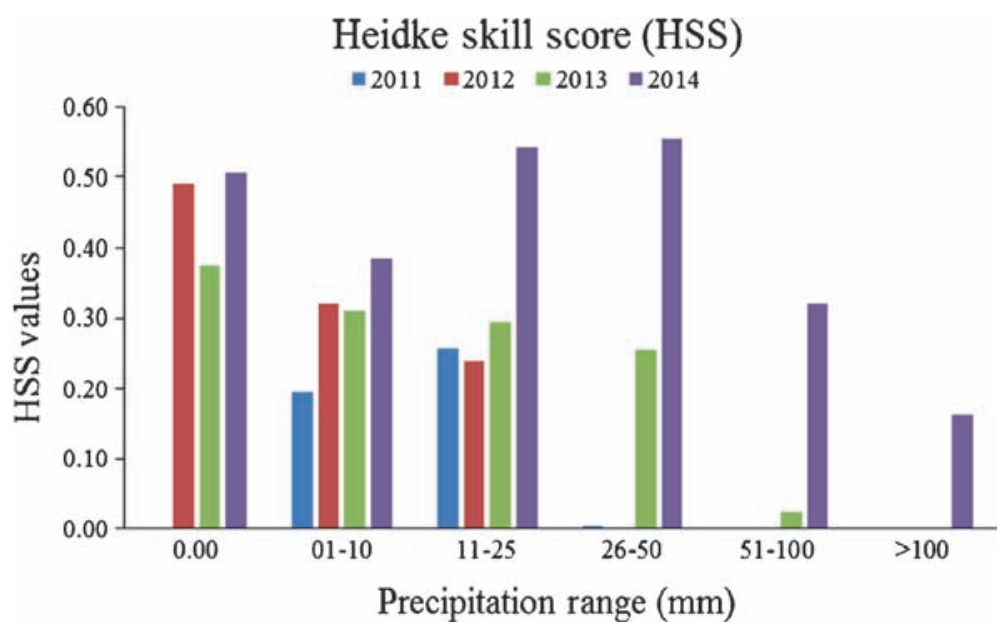

Figure 10. Heidke skill score (HSS) for forecasting of flood over the FMO Patna region during the years 2011-2014. 


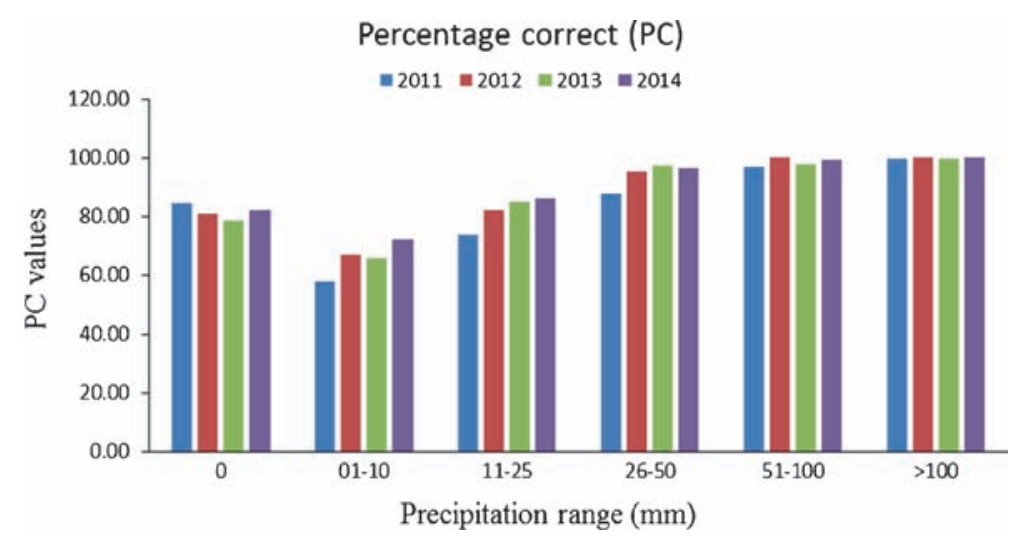

Figure 11. Percentage correct (PC) values for forecasting of flood over the FMO Patna region during the years 2011-2014.

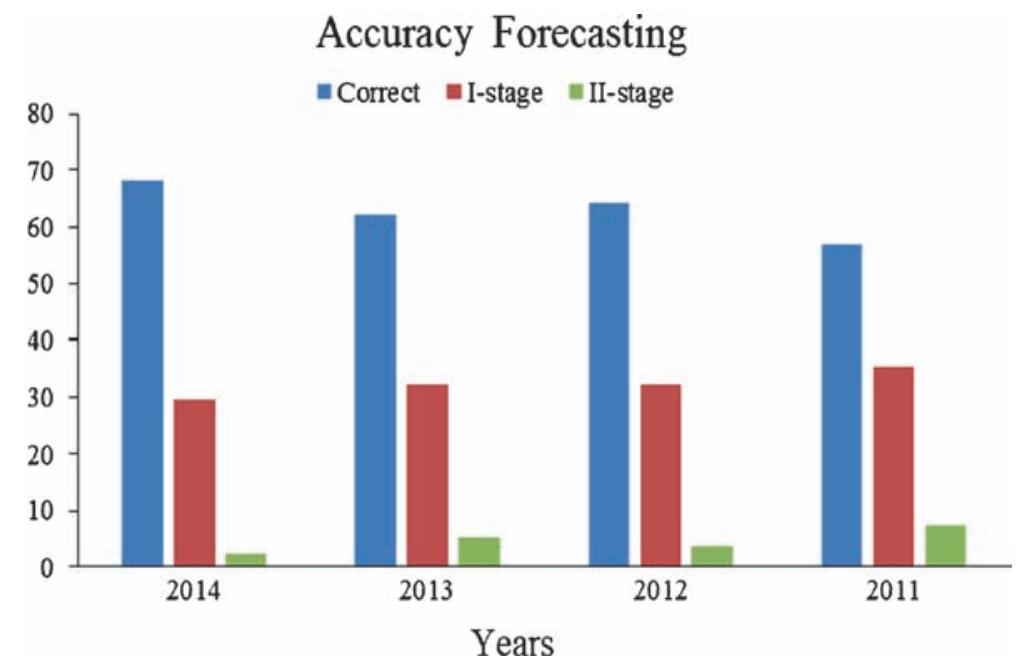

Figure 12. Accuracy of forecasting of flood over the FMO Patna region during the years 2011-2014.

Tenasserim coast. This cyclonic system intensified into a storm named Phailin on October 9 and as a severe and very severe cyclone on the following day. It crossed Odisha and adjoining north Andhra Pradesh coast near Gopalpur around 2230 hrs Indian Standard Time (IST) on October 12 (figure 13). The cyclonic system entered into Bihar as a depression on October 14 (figure 13).

Station and KALPANA-1 observed rainfall are compared with the MME-predicted rainfall for different basins in FMO Patna region during the occurrence of tropical cyclone Phailin especially for October 13, 14 and 15 (table 3). There is a large difference in MME-predicted rainfall and the estimated amount from KALPANA-1 though the horizontal resolutions of both the products are similar. This is because the estimated rainfall from KALPANA-1 through IMSRA normally shows a reasonable areal distribution but it underestimates the precipitation amount as compared to the one from MME in case of a well-organized system with persistent convection like that of Phailin.
On October 13, the MME-based precipitation forecast is found to be better as compared to the KALPANA-1 derived QPE. It is because the normalized mean square error (NMSE) value is relatively less in case of MME $(\sim 4.12)$ as compared to that of KALPANA-1 $(\sim 6.23)$. On the other hand, the errors are profoundly higher on October $14(\sim 18.6)$ and $15(\sim 27)$ for MME prediction as when compared to those from KALPANA1 ( $\sim 4.2$ and 3.27 respectively). Thus, it appears that the MME-based QPF is probably not reliable for extreme rainfall cases. However, the MME is still able to qualitatively show that the AAP distribution is higher on October 14 and 15 (figures $14 \mathrm{~b}-\mathrm{c}$ ) as compared to that of October 13 (figure 14a) in the FMO Patna region. This is expected since the cyclonic system entered into this region on October 14 (figure 13) and subsequently causing more rainfall on October 14 and 15 (figures $14 \mathrm{~b}-\mathrm{c}$ ) as compared to October 13 (figure 14a). This is also supported by the observational evidence as reported by IMD (IMD 2013). Therefore, QPF forecasting through MME in particular is still 


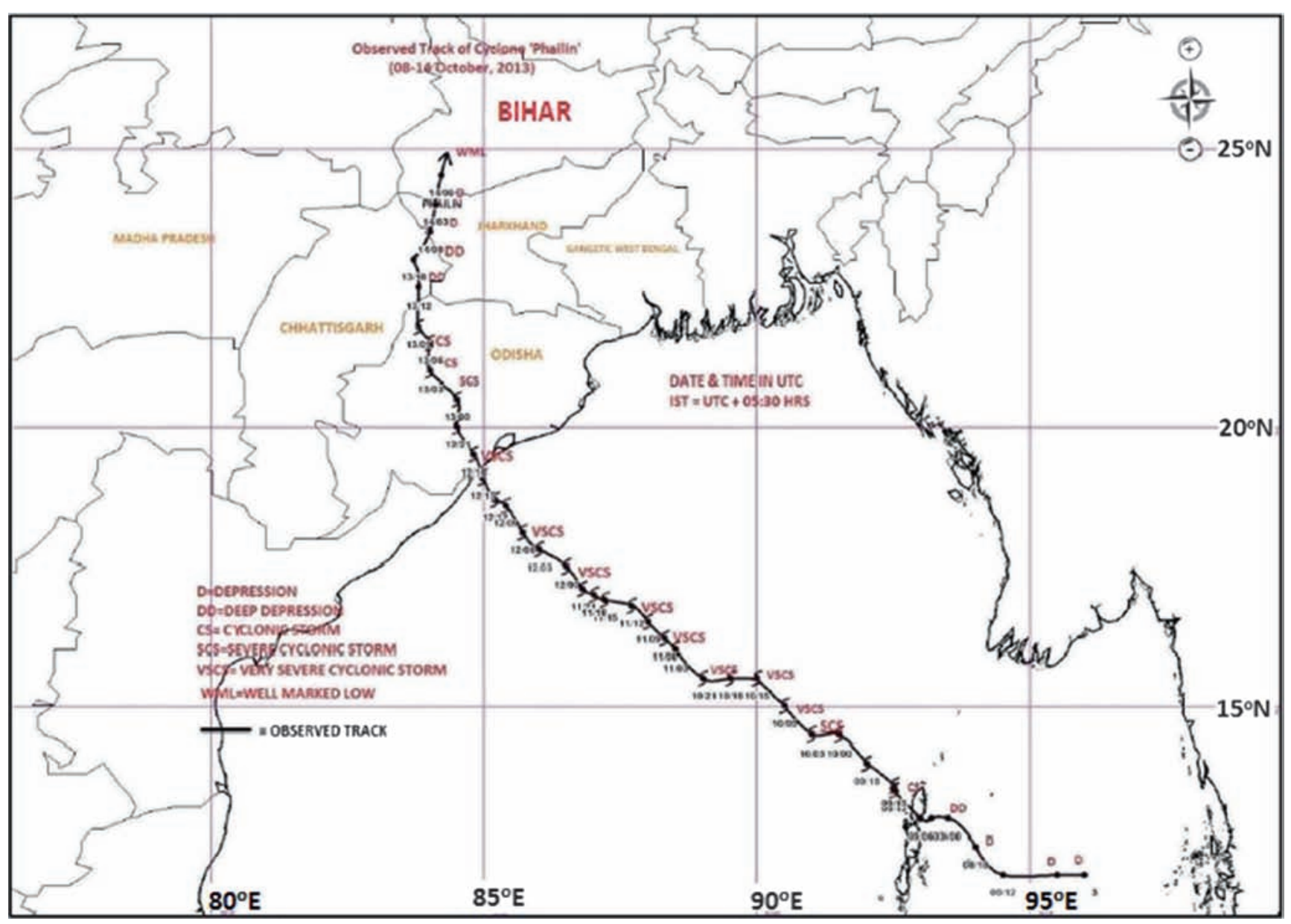

Figure 13. Observed track of Phailin very severe tropical cyclone during October 8-14, 2013 (IMD Phailin Report 2013).

Table 3. Station and KALPANA-1 satellite observed and MME-predicted rainfall for different basins in FMO, Patna region during tropical cyclone Phailin.

\begin{tabular}{|c|c|c|c|c|c|c|c|c|c|}
\hline \multirow[b]{2}{*}{$\begin{array}{l}\text { Station } \\
\text { name }\end{array}$} & \multicolumn{3}{|c|}{ Date $13-10-2013$} & \multicolumn{3}{|c|}{ Date $14-10-2013$} & \multicolumn{3}{|c|}{ Date 15-10-2013 } \\
\hline & $\begin{array}{l}\text { Station } \\
\text { observed }\end{array}$ & $\begin{array}{c}\text { KALPANA-1 } \\
\text { QPE }\end{array}$ & MME & $\begin{array}{l}\text { Station } \\
\text { observed }\end{array}$ & $\begin{array}{c}\text { KALPANA-1 } \\
\text { QPE }\end{array}$ & MME & $\begin{array}{l}\text { Station } \\
\text { observed }\end{array}$ & $\begin{array}{l}\text { LPAN } \\
\text { QPE }\end{array}$ & MME \\
\hline Gandak & 13.4 & 4.2 & 54 & 1154.2 & 165 & 77 & 629.1 & 209 & 39 \\
\hline $\begin{array}{l}\text { Bagmati- } \\
\text { Adhwara }\end{array}$ & 1 & 2.4 & 49 & 805 & 156 & 82 & 454.7 & 211 & 68 \\
\hline $\begin{array}{l}\text { Kosi- } \\
\text { Mahananda }\end{array}$ & 11.7 & 8.4 & 51 & 883 & 189 & 72 & 1413.62 & 249 & 50 \\
\hline $\begin{array}{l}\text { North Koel- } \\
\text { Kanhar }\end{array}$ & 84.9 & 29.4 & 75 & 719.2 & 197 & 28 & 94 & 35 & 3 \\
\hline Pupun & 32.4 & 16.8 & 86 & 352.4 & 121 & 36 & 67.3 & 24 & 5 \\
\hline East Pupun & 476.3 & 130.2 & 78 & 1629 & 241 & 25 & 574.7 & 242 & 19 \\
\hline
\end{tabular}

useful in order to issue a warning for flood during an extreme weather event like the cyclonic storm Phailin.

\section{Concluding remarks}

Quantitative forecasting of precipitation is a gigantic task for operational agencies like IMD in both climatologically as well as during extreme weather events. For this purpose, MME-based QPF may be used instead of a single numerical model based rainfall forecasting (Krishnamurti et al. 1999; Das et al. 2011; Mitra et al. 2011; Roy Bhowmik and Durai 2012) besides referring to the observations from satellites, radars and ground stations. However, it is important to understand whether the 


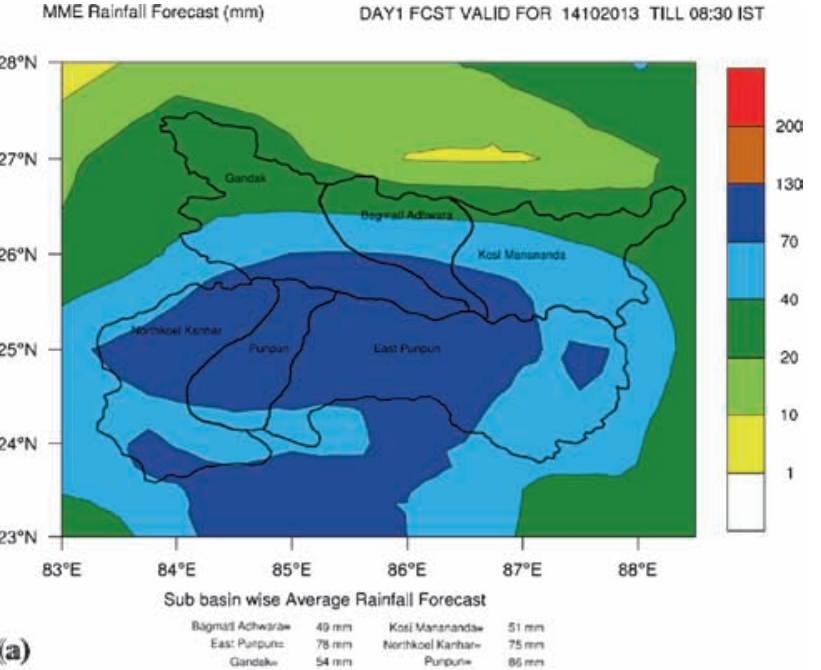

MME Rainfall Forecast (mm) DAY2 FCST VALID FOR 15102013 TILL 08:30 IST

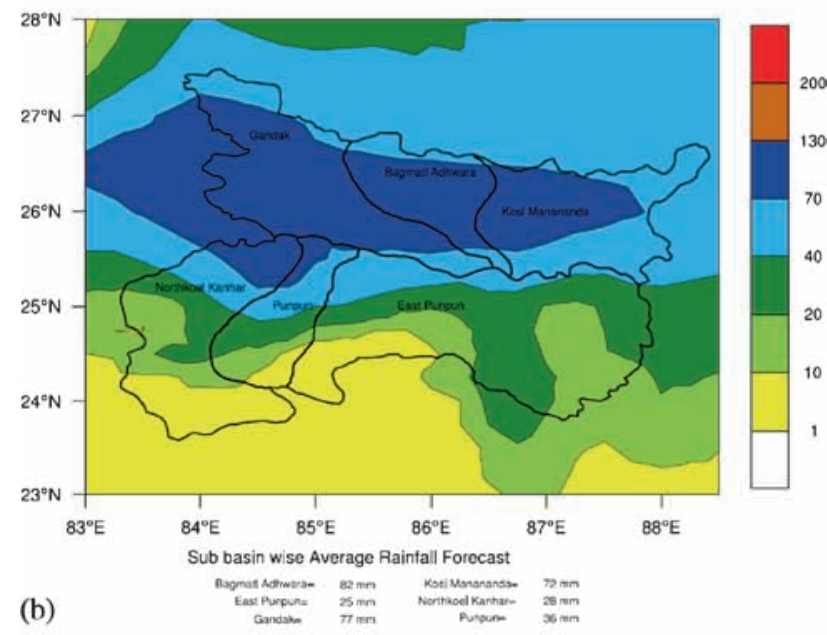

MME Rainfal Forecast (mm) DAY3 FCST VALID FOR 16102013 TILL 08:30 IST

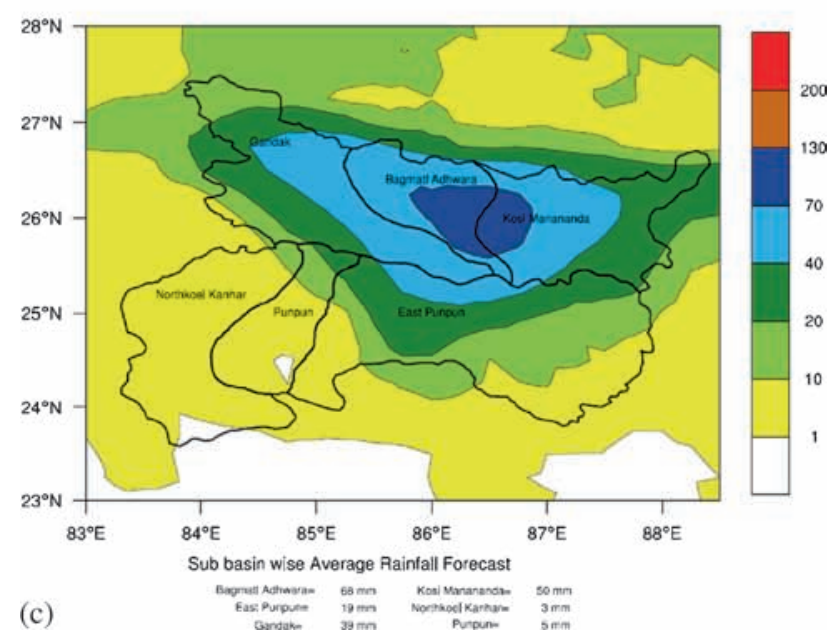

Figure 14. (a) Multi-model ensemble (MME) rainfall forecast valid for October 14, 2013 (day 1) till 8:30 IST. (b) Multi-model ensemble (MME) rainfall forecast valid for October 15, 2013 (day 2) till 8:30 IST. (c) Multi-model ensemble (MME) rainfall forecast valid for October 16, 2013 (day 3) till 8:30 IST.
MME-based QPF is appreciably close to the realistic values. In view of this, the present study attempts to validate the MME-based QPF from IMD by analysing several statistical indices for precipitation ranges $<1,1-10,11-25,26-50,51-$ 100 and $>100 \mathrm{~mm}$ during 2011-2014 over the FMO Patna region. The forecasting issued by FMO Patna is primarily emphasized for these years in order to understand the situation when a warning can be issued for the occurrence of flood. Further, one extreme weather case during the occurrence of cyclonic storm Phailin is considered to see whether the forecasting issued during such events is reliable or not.

The QPF analysis and validation for the years 2011-2014 suggests that the forecasting is more reliable in the precipitation ranges $1-10 \mathrm{~mm}$ and 11-25 mm. However, the reliability decreases for higher ranges of rainfall and also for the lowest range, i.e., below $1 \mathrm{~mm}$. In case of extreme events like tropical cyclone Phailin, the MME forecasting is qualitatively useful for issuing a warning for the occurrence of floods though it may not be reliable for the QPF. This finding is similar to that of Mandal et al. (2007). The Phailin case study used in this work serves as an example to extreme precipitation events where floods can occur due to low to moderate rainfall for a considerable duration.

Overall purpose of QPF is to achieve the closer estimate to the actual rainfall. This may be achieved by issuing the forecasts based on synoptic analysis. MME from numerical models or satellite or even radar precipitation can help to improve the synoptic based analysis. Therefore, the degree of correctness in QPF can be increased after adopting the value addition from satellite measurements (e.g., INSAT-3D) and radar (Doppler Weather Radar) measurements though MME can still be handy enough to issue warning for the occurrence of floods. On the other hand, only one method may not be sufficient in a changing climate scenario and thus, the traditional approach needs appropriate modifications. An integrated framework is essential in order to get an appropriate QPF closer to the observations. In this study, synoptic analysis based MME output gives a clue (after all this is also a model based forecast value) and the satellite based instant prediction may help to revise the prediction. However, only having satellite products as support, may not serve the purpose since they have their own limitations being estimated values (based on some algorithms, which are designed using some assumptions). Sometimes, rainfall is underestimated or overestimated through the adopted algorithm. Incorporating more passive (satellite) and/or active (radar) remote sensing data through assimilation process in numerical models before 
preparing an MME or a grand ensemble would probably reduce the gap between the observed and predicted precipitation values and help in better flood forecasting.

\section{Acknowledgements}

Authors are grateful to the Director General of Meteorology for the accomplishment of this work. The suggestions and help of Regional Meteorological Centre Patna staffs are also duly acknowledged. The authors would also like to appreciate and express their thanks for the valuable comments and suggestions from the anonymous reviewers, which helped in overall improvement of the manuscript.

\section{Appendix}

The simplest forecast can be categorically either 'yes' or 'no' forecast of occurrence of a phenomenon like a rain event. In order to understand the verification measures used for forecast evaluation let us consider a contingency table as follows:

\begin{tabular}{lll}
\hline \multirow{2}{*}{ Observed } & \multicolumn{2}{c}{ Forecast } \\
\cline { 2 - 3 } & Yes & No \\
\hline Yes & X1 & X2 \\
No & Y1 & Y2 \\
\hline
\end{tabular}

In this table, $\mathrm{X} 1$ indicates the case when the event (the flood in this case) is actually observed (observed occurrence) and also predicted to occur (forecast occurrence). Y1 indicates an event which is not observed in reality (observed non-occurrence) whereas it is predicted to occur. When an event is predicted not to occur (forecast non-occurrence) whereas it occurs in reality then it is classified as $\mathrm{X} 2$ otherwise (observed non-occurrence) it is denoted by Y2. In view of this, the total number of forecasts generated is given by

$$
\mathrm{TF}=\mathrm{X} 1+\mathrm{X} 2+\mathrm{Y} 1+\mathrm{Y} 2 .
$$

Now, the probability of detection (POD) can be written as:

$$
\mathrm{POD}=\frac{\mathrm{X} 1}{\mathrm{X} 1+\mathrm{X} 2}
$$

False alarm rate (FAR) is given by the following equation:

$$
\mathrm{FAR}=\frac{\mathrm{Y} 1}{\mathrm{X} 1+\mathrm{Y} 1} .
$$

Missing rate (MR) is calculated as:

$$
\mathrm{MR}=\frac{\mathrm{X} 2}{\mathrm{X} 1+\mathrm{X} 2} .
$$

Similarly, the values of correct non-occurrence of $\mathrm{C}-\mathrm{NON}$ can be computed as:

$$
\mathrm{C}-\mathrm{NON}=\frac{\mathrm{Y} 2}{\mathrm{Y} 1+\mathrm{Y} 2} \text {. }
$$

The critical success index (CSI) is given by:

$$
\mathrm{CSI}=\frac{\mathrm{X} 1}{\mathrm{X} 1+\mathrm{X} 2+\mathrm{Y} 1} \text {. }
$$

Bias for occurrence (abbreviated as BIAS) of the event can be computed as:

$$
\mathrm{BIAS}=\frac{\mathrm{X} 1+\mathrm{Y} 1}{\mathrm{X} 1+\mathrm{X} 2}
$$

Percentage correct $(\mathrm{PC})$ values can be computed as:

$$
\mathrm{PC}=\frac{\mathrm{X} 1+\mathrm{Y} 2}{\mathrm{TF}} \times 100 \% .
$$

True skill score (TSS) can be determined by the following formulation:

$$
\mathrm{TSS}=\frac{\mathrm{X} 1}{\mathrm{X} 1+\mathrm{X} 2}+\frac{\mathrm{Y} 2}{\mathrm{Y} 1+\mathrm{Y} 2}-1 .
$$

Similarly, another skill score known as Heidke skill score (HSS) can be computed in a relatively complex manner as follows:

$$
\begin{aligned}
& \mathrm{HSS}= \frac{2\{(\mathrm{X} 1)(\mathrm{Y} 2)-(\mathrm{X} 2)(\mathrm{Y} 1)\}}{(\mathrm{X} 2)^{2}+(\mathrm{Y} 1)^{2}+2(\mathrm{X} 1)(\mathrm{Y} 2)} \\
&+(\mathrm{X} 2+\mathrm{Y} 1)(\mathrm{X} 1+\mathrm{Y} 2)
\end{aligned}
$$

\section{References}

Agnihotri G and Panda J 2014 Comparison of rainfall from ordinary and automatic rain gauges in Karnataka; Mausam 65(4) 575-584.

Apte N Y, Kaur S and Das A K 2011 Performance of IMD multi-model ensemble and WRF based sub-basin wise rainfall forecast for Mahanadi basin during Flood Season (Monsoon) 2009 and 2010, Met Monograph: Synoptic Meteorology No. 11/2011, IMD.

Das A K, Gupta A K, Halder R N, Laxmi V and Awasthi J 2011 Performance of IMD multi-model ensemble (MME) and WRF (ARW) based sub-basin wise rainfall forecast for Mahanadi basin during flood season 2011; Vayu Mandal 37 110-122.

Das S, Kar N S and Bandyopadhyay S 2015 Glacial lake outburst flood at Kedarnath, Indian Himalaya: A study using digital elevation models and satellite images; Natural Hazards 77 769-786.

Dhar O N and Nandergi S 1993 Spatial distribution of severe rainstorms over India and their associated rainfall depths; Mausam 44 373-380.

Gerapetritis H and Pelissier J M 2004 On the behavior of the critical success index; Eastern region technical attachment, No. 2004-03.

Gibergans-Báguena J and Llasat M C 2007 Improvement of the analog forecasting method by using local thermodynamic data. Application to autumn precipitation in Catalonia; Atmos. Res. 86 173-193. 
Giri R K, Prakash S, Kumar R and Panda J 2012 Significance of scatterometer winds data in weak vortices diagnosis in Indian seas; Int. J. Phys. Math. Sci. 2 19-26.

Goswami B N, Venugopal V, Sengupta D, Madhusoodanan M S and Xavier P K 2006 Increasing trend of extreme rain events over India in a warming environment; Science 134 1442-1445.

Guhathakurta P, Sreejith O P and Menon P A 2011 Impact of climate change on extreme rainfall events and flood risk in India; J. Earth Syst. Sci. 120 359-373.

IMD 2013 Very severe cyclonic storm Phailin over the Bay of Bengal (08-14 October 2013): A report. Cyclone Warning Division, India Meteorological Department New Delhi, 43p, http://www.imd.gov.in/section/nhac/ dynamic/phailin.pdf.

IPCC 2007 Climate change 2007: Synthesis report; 52p, https://www.ipcc.ch/pdf/assessment-report/ar4/syr/ ar4_syr.pdf.

Krishnamurti T N, Kishtawal C M, LaRow T E, Bachiochi D R, Zhang Z, Williford C E, Gadgil S and Surendran S 1999 Improved weather and seasonal climate forecasts from multi-model superensemble; Science 285 1548-1550.

Lal J, Day J S and Kapoor K K 1989 Synoptic analogue method for issue of semi QPF for Gomati catchment; Mausam 34 309-312.

Mandal V, De U K and Basu B K 2007 Precipitation forecast verification of the Indian summer monsoon with intercomparison of three diverse regions; Wea. Forecasting 22 428-443.

Mirza M M Q 2003 Three recent extreme floods in Bangladesh: A hydro-meteorological analysis; Natural Hazards 28 35-64.

Mitra A K, Iyengar G R, Durai V R, Sanjay J, Krishnamurti T N, Mishra A and Sikka D R 2011 Experimental realtime multi-model ensemble (MME) prediction of rainfall during monsoon 2008: Large-scale medium-range aspects; J. Earth Syst. Sci. 120 27-52.

Mohanty U C and Dimri A P 2004 Location-specific prediction of the probability of occurrence and quantity of precipitation over western Himalayas; Wea. Forecasting 19 $520-533$.
Mohanty U C, Ravi N and Madan O P 2001 Forecasting precipitation over Delhi during the southwest monsoon season; Meteorol. Appl. 8 11-21.

Panda J and Giri R K 2012 A comprehensive study of surface and upper air characteristics over two stations on the west coast of India during the occurrence of a cyclonic storm; Natural Hazards 64 1055-1078.

Panda J, Giri R K, Patel K H, Sharma A K and Sharma R K 2011 Impact of satellite derived winds and cumulus physics during the occurrence of the tropical cyclone Phyan; Indian J. Sci. Technol. 4 859-875.

Panda J, Singh H, Giri R K and Routray A 2015 A qualitative study of some of the meteorological features during tropical cyclone PHET using satellite observations and WRF modeling system; J. Indian Soc. Remote Sens. 43 45-56.

Ram L C and Kaur S 2004 Quantitative precipitation forecast for Upper Yammuna Catchment by synoptic analogue method; Mausam 55 508-511.

Ram L C and Pangasa N K 2000 Semi-quantitative precipitation forecast for Ghagra catchments by synoptic analogue method; Mausam 51 85-87.

Ray K and Patel D M 2000 Semi-QPF model for River Narmada by Synoptic Analogue method; Mausam 51 88-90.

Ray K and Sahu M L 1998 A synoptic analogue model for QPF of river Sabarmati basin; Mausam 49 499-502.

Roy Bhowmik S K and Durai V R 2012 Development of multi-model ensemble based district level medium range rainfall forecast system for Indian region; J. Earth Syst. Sci. 121 273-285.

Schaefer J T 1990 The critical success index as an indicator of warning skill; Wea. Forecasting 5 570-575.

Singh K M, Prasad M C and Prasad G 2010a Semi quantitative forecasts for Baghmati/Adhwara Group of rivers/Kamala Balan catchments by synoptic analogue technique; Mausam 61 337-348.

Singh K M, Prasad M C, Prasad G, Prasad R and Jha M K 2010b Semi-quantitative precipitation forecasts for Kosi/Mahananda catchment by synoptic analogue method; Mausam 61 175-186. 